\title{
ЗЕЛЕНАЯ ТРАНСФОРМАЦИЯ НЕФТЕГАЗОВЫХ МЕЙДЖОРОВ: НАЧАЛЬНЫЙ ЭТАП
}

\section{Н.А. Иванов 1}

С началом 2020 года крупнейшие международные нефтегазовые компании резко ускорили изменение своих инвестиционных стратегий в направлении декарбонизации бизнеса и поддержки достижения целей Парижского соглашения. Изменения происходят с двух направлений: с одной стороны, крупные международные инвестиционные фонды принимают решения отказаться от вложений в нефтегазовый бизнес, с другой - сами нефтегазовые компании заявляют о «зеленой» трансформации своего бизнеса.

Вероятно, эти тенденции взаимосвязаны - инвесторы и крупнейшие компании, представляющие традиционный сырьевой энергетический бизнес, должны найти способ удовлетворить потребности друг друга и представить дело так, чтобы экологически обеспокоенная мировая общественность не чувствовала себя обманутой. Необходимо найти разумный баланс между доходностью инвестиций и развитием чистых энергетических технологий.

Сегодня уже практически все нефтегазовые мейджоры опубликовали заявления, декларации, программы перехода к низкоуглеродному пути развития своего бизнеса. Необходимо разобраться, насколько эти намерения в действительности меняют траекторию развития бизнеса корпораций в направлении чистой энергетики - или они являются всего лишь «дымовой завесой», необходимой для удовлетворения обеспокоенности инвесторов и дающей возможность продолжать традиционный бизнес по освоению нефтегазовых ресурсов.

Данное исследование едва ли сможет дать однозначный ответ на вопрос, является ли «зеленая» трансформация нефтегазового бизнеса принципиальной сменой инвестиционной парадигмы крупнейших компаний или ее имитацией, попыткой встроиться в современные тренды публичной политики.

Дело в том, что проведенный анализ объясняет различное отношение компаний к климатическим вызовам: одни надеются на возможное смягчение требований к углеродной интенсивности бизнеса, позволяющее адаптировать текущие операции к целевым уровням декарбонизации, другие - демонстрируют стремление возглавить движение к ускоренному формированию низкоуглеродной энергетики будущего. Но всех представителей нефтегазового бизнеса роднит то, что изменение своей инвестиционной стратегии они рассматривают как часть стратегии управления рисками. И все различия в стратегиях определяются разной оценкой климатических

\footnotetext{
${ }^{1}$ Иванов Николай Александрович - кандидат экономических наук, доцент Кафедры международного нефтегазового бизнеса РГУ нефти и газа (НИУ) имени И.М. Губкина
} 
рисков и разными подходами к управлению ими. В данном случае речь идет об инвестиционных рисках, связанных с ошибочным пониманием направлений развития нефтегазовой отрасли, которые, в свою очередь, определяются господствующими мировыми тенденциями в отношении проблемы изменения климата.

Различные подходы к управлению климатическими рисками, применяемые международными нефтегазовыми мейджорами, влияют на инвестиционную привлекательность проектов в отрасли и финансовую оценку их будущей доходности.

Можно предположить, что главным двигателем происходящих в отрасли изменений в части ее опережающей дакарбонизации выступают не сами нефтегазовые компании, а крупные группы международных инвесторов, транслирующие господствующие общественные настроения на свои инвестиционные предпочтения. И компании вынуждены учитывать эти изменения в настроениях финансовых рынков при формировании собственных долгосрочных стратегий развития и при долгосрочной оценке соответствующих рисков. Таким образом, по текущим действиям международных нефтегазовых мейджоров можно оценить долгосрочные инвестиционные перспективы нефтегазовой отрасли, поскольку мировая «мода» на «зеленые» инвестиции неизбежно отразится и на доходности нефтегазовых активов вообще, и на позициях российской нефтегазовых компаний, в частности.

\section{«Зеленое» увлечение мейджоров}

C началом 2020 года, еще до начала коронавирусной пандемии COVID-19, ведущие европейские нефтегазовые компании стали одна за другой заявлять о резкой смене инвестиционной стратегии в направлении развития низкоуглеродных направлений бизнеса. Побудительной мотивацией для такого заметного разворота инвестиционной парадигмы европейских компаний могло стать принятие в декабре 2019 года т.н. «Зеленого пакта» (Green Deal) — плана мероприятий по превращению Европы в «первый климатически нейтральный континент» к 2050 году, и последовавшие за этим событием заявления руководства ряда крупных банков о пересмотре инвестиционной политики последних в отношении проектов в сфере углеводородной энергетики.

Первой нефтегазовой компанией, еще в декабре 2019 г. заявившей о стремлении к 2050 году добиться углеродной нейтральности бизнеса, стала испанская Repsol2.

В январе 2020 г. норвежская Equinor заявила о намерении снизить эмиссии углерода от своих операций в Норвегии на 40\% к 2030 г., на 70\% к 2040 г. и приблизить к нулю

\footnotetext{
${ }^{2}$ https://www.repsol.com/en/press-room/press-releases/2019/repsol-will-be-a-net-zeroemissions-company-by-2050.cshtml
} 
к 2050 г.3 Уже в начале февраля компания объявила о планах вдвое снизить углеродную интенсивность своего глобального бизнеса к 2050 году. 4

Новый глава компании британской компании ВР Бернард Луни уже через неделю после своего назначения в феврале 2020 г. объявил о цели достичь углеродной нейтральности бизнеса компании к 2050 году. ${ }^{5}$ Не заставили себя ждать Shell ${ }^{6}$, Total ${ }^{7}$ и Eni8- объявить новые амбициозные цели низкоуглеродного развития стало вопросом престижа для европейских нефтегазовых компаний.

Перечисленные компании параллельно с целями по декарбонизации нефтегазового бизнеса активно развивают проекты в сфере возобновляемой энергетики, которые занимают все более заметное место в их инвестиционном портфеле.

Волатильность нефтяного рынка, вызванная пандемией коронавируса COVID -19 весной 2020 г., добавила сомнений в долгосрочных перспективах нефтегазового бизнеса. Спрос на нефть упал, следом снизились нефтяные и газовые цены, компании стали отказываться от реализации проектов, рентабельность которых вызывает сомнения - одна только Shell списала нефтегазовых активов на \$22 млрд.

Конечно, волатильность всегда была свойственна нефтяному рынку, и нефтегазовые мейджоры имеют богатый опыт работы в условиях неблагоприятной конъюнктуры. Но сегодняшняя ситуация имеет свою специфику.

Во-первых, с точки зрения потребителей низкие цены на энергоносители не всегда однозначное благо. Речь об энергетической безопасности: сегодня цена низкая, рынок затоварен дешевым топливом, но завтра ситуация изменилась - изобилие сменилось дефицитом, цены растут и бьют по экономике и благосостоянию населения. Во-вторых, существенен психологический момент: когда потребители энергоресурсов понимают, что их благосостояние и безопасность зависят от договоренностей ОПЕК и других стран - производителей нефти, от игр на финансовом нефтяном рынке, от торговой войны США и Китая - долгосрочной уверенности в экономической стабильности это не прибавляет. В этом смысле распределенная возобновляемая энергетика, недостатком которой является ее природная нестабильность, а не рыночная волатильность, может представляться предпочтительнее - даже при условии своей относительной дороговизны. Но снижение стоимости ВИЭ - вопрос развития технологий, а не биржевых манипуляций, что, зачастую, более понятно и приемлемо для потребителей.

\footnotetext{
${ }^{3}$ https://www.equinor.com/en/news/2020-01-06-climate-ambitions-norway.html

${ }^{4}$ https://www.equinor.com/en/news/2020-02-06-climate-roadmap.html

${ }^{5}$ https://www.bp.com/en/global/corporate/who-we-are/reimagining-energy.html

${ }^{6}$ https://www.shell.com/energy-and-innovation/the-energy-future/shells-ambition-to-be-a-netzero-emissions-energy-business.html

7 https://www.total.com/media/news/total-adopts-new-climate-ambition-get-net-zero-2050

${ }^{8}$ https://www.eni.com/en-IT/investors/long-term-plan.html
} 
Разумеется, интересы потребителей - это не то, что в первую очередь беспокоит нефтяные компании. Важнее отношения с инвесторами. Многие крупные инвестиционные фонды в последнее время заявляли об отказе вложений в нефтегазовый бизнес. Но для них это, в первую очередь, вопрос имиджа - и здесь удовлетворение запросов и даже учет предубеждений потребителей играет определяющую роль.

В таких условиях для нефтяных компаний остаются два выхода - либо заявить, что они проводят коренную трансформацию своего бизнеса и, по сути, превращаются из нефтегазовых компаний в энергетические, ориентированные на чистые и возобновляемые источники энергии (европейский путь) либо - доказать, что главный смысл энергетической трансформации - не изменение корзины производимых энергоресурсов, а снижение эмиссии парниковых газов (американский путь).

Так, американские нефтегазовые мейджоры сосредоточены на проектах CCUS (улавливания, использования и захоронения углерода), сокращения объемов сжигания попутного газа, снижения утечек метана и т.п. методах повышения экологической привлекательности своих традиционных нефтегазовых проектов. Для поддержки такого подхода создана целая сеть организаций, выступающих за «ответственное инвестирование».

Таким образом, дискуссия о судьбе традиционного нефтегазового бизнеса постепенно смещается от выбора между добычей ископаемых энергоресурсов и развитием технологий возобновляемой энергетики к вопросу об экологической нагрузке от деятельности энергетических компаний, или, как это теперь называется, «углеродной интенсивности» бизнеса.

Углеродная интенсивность стала тем количественным показателем, который призван примирить два подхода и перевести вопрос из медийной плоскости в технологическую. Неважно, какими способами компании собираются добиться углеродной нейтральности, главное - результат можно будет оценить и предъявить общественности и инвесторам.

В качестве примера можно привести данные по углеродной интенсивности бизнеса BP, поскольку эта компания выступает пионером в предоставлении такой информации (Табл. 1$).{ }^{9}$

Очевидно, что в обозримом будущем мир не готов будет отказаться от нефти и газа, поэтому вопрос примирения нефтегазового бизнеса и экологических запросов общества необходимо решить как можно скорее и в наиболее взаимоприемлемой форме. Пока же и для нефтяных компаний, и для общества стоит вопрос управления климатическими рисками. Даже если понимаются эти риски по-разному.

Климатические риски - не единственные, принимаемые в расчет компаниями. Реагирования требуют многочисленные вызовы, объединяемые понятием

\footnotetext{
${ }^{9}$ https://www.bp.com/content/dam/bp/businesssites/en/global/corporate/pdfs/sustainability/bp-esg-datasheet-2019.pdf
} 
«устойчивое развитие». Ежегодные доклады об устойчивом развитии являются частью стандартной отчетности акционерных компаний и касаются полного спектра проблем, обозначенных целями $\mathrm{OOH}$ по устойчивому развитию10. Нефтегазовые компании особое внимание уделяют целям 7 (Доступная чистая энергия), 8 (Экономическое развитие и рабочие места) и 13 (Борьба с изменением климата) ${ }^{11}$.

Таблица 1. Эмиссии парниковых газов в отчетности ВР при операциях с собственными активами

\begin{tabular}{|c|c|c|c|c|c|c|}
\hline Показатель & Единица & 2015 & 2016 & 2017 & 2018 & 2019 \\
\hline $\begin{array}{l}\text { Прямые эмиссии парниковых } \\
\text { газов (Scope 1) }\end{array}$ & т СО2-экв. & 49,0 & 50,1 & 49,4 & 46,5 & 46,0 \\
\hline $\begin{array}{l}\text { Прямые эмиссии СО2 (Scope } \\
\text { 1) }\end{array}$ & т СО2-экв. & 45,1 & 46,1 & 45,8 & 43,3 & 43,0 \\
\hline $\begin{array}{l}\text { Прямые эмиссии метана } \\
\text { (Scope 1) }\end{array}$ & $\mathrm{T}$ & 0,16 & 0,16 & 0,15 & 0,13 & 0,12 \\
\hline \multicolumn{7}{|l|}{ Интенсивность эмиссий } \\
\hline Добыча & т СО2-экв. на тыс. бнэ & 32,7 & 34,7 & 30,4 & 27,8 & 25,9 \\
\hline Переработка & $\begin{array}{l}\text { т СО2-экв. на эквивалент } \\
\text { использованной мощности } \\
\text { переработки }\end{array}$ & 944 & 951 & 923 & 915 & 916 \\
\hline Нефтехимия & т СО2-экв. на тыс. т & 290 & 287 & 304 & 289 & 291 \\
\hline Непрямые эмиссии (Scope 2) & т СО2-экв. & 6,9 & 6,2 & 6,8 & 5,7 & 5,7 \\
\hline $\begin{array}{l}\text { Углеродные эмиссии при } \\
\text { добыче нефти и газа }\end{array}$ & т СО2-экв. & & & & & 357,3 \\
\hline $\begin{array}{l}\text { Средняя интенсивность } \\
\text { эмиссий от реализованной } \\
\text { продукции }\end{array}$ & г СО2-экв/МДж & & & & & 79,7 \\
\hline $\begin{array}{l}\text { Интенсивность эмиссий от } \\
\text { произведенных } \\
\text { нефтепродуктов }\end{array}$ & г СО2-экв/МДж & & & & & 93,7 \\
\hline $\begin{array}{l}\text { Интенсивность эмиссий от } \\
\text { газовой продукции }\end{array}$ & г СО2-экв/МДж & & & & & 71,6 \\
\hline
\end{tabular}

10 Цели в области устойчивого развития (ЦУР) (Sustainable Development Goals, SDGs), официально известные, как «Преобразование нашего мира: повестка дня в области устойчивого развития на период до 2030 года» (Transforming our world: the 2030 Agenda for Sustainable Development) - набор целей для будущего международного сотрудничества, которые заменили собой Цели развития тысячелетия в конце 2015 года. Эти цели планируется достигать с 2015 по 2030 годы. Итоговый документ содержит 17 глобальных целей и 169 соответствующих задач.

${ }^{11}$ https://www.un.org/sustainabledevelopment/ru/sustainable-development-goals/ 


\begin{tabular}{|c|c|c|c|c|c|c|}
\hline $\begin{array}{l}\text { Интенсивность эмиссий от } \\
\text { биотоплива }\end{array}$ & г СО2-экв/МДж & & & & & 28.8 \\
\hline $\begin{array}{l}\text { Интенсивность эмиссий от } \\
\text { электрогенерации }\end{array}$ & г СО2-экв/МДж & & & & & 43.8 \\
\hline $\begin{array}{l}\text { Эмиссии от реализованной } \\
\text { продукции за весь } \\
\text { жизненный цикл }\end{array}$ & т СО2-экв. & & & & & 1012.5 \\
\hline $\begin{array}{l}\text { Эмиссии СО2,замещенные } \\
\text { развитием ВИЭ }\end{array}$ & MteCO2e & 3.3 & 2.8 & 2.7 & 2.8 & 2.3 \\
\hline
\end{tabular}

Источник: BP EGS Datasheet 2019

Но если следование большинству целей предполагает планомерное совершенствование производственных процессов и изменение отношения к актуальным проблемам, таким как защита природной среды и биоразнообразия или обеспечение гендерного равенства, то борьба с изменением климата требует коренной перестройки бизнеса. И игнорирование складывающихся тенденций грозит ухудшением конкурентного положения. Поэтому климатические риски выходят на первый план.

\section{Управление климатическими рисками}

Опасность собственно климатических изменений и оценка связанных с ними рисков для природной среды, мировой экономики и человеческой деятельности выходит за рамки данного исследования, которое посвящено пониманию этих вопросов именно руководителями и инвесторами компаний нефтегазового сектора.

С точки зрения нефтяников, оценка и управление климатическими рисками означает усилия по обеспечению безопасности операций и генерации прибыли для инвесторов. Поэтому климатические риски относятся к категории стратегического планирования и принятия инвестиционных решений и требуют оценки с точки зрения готовности оперативно реагировать на возникающие чрезвычайные ситуации и открывающиеся благоприятные возможности.

При этом оценивается широкий спектр возможностей и угроз как технического и технологического порядка, так и вопросы возможных законодательных и регуляторных изменений, геополитики, прогнозы экономического развития и цен на сырьевые товары, региональные проблемы. При оценке новых проектов - и это напрямую относится к оценке климатических рисков в понимании нефтяных компаний - особое внимание уделяется вопросам будущего уровня цен на углеродные эмиссии.

Как бы ни относиться к прогнозам и сценариям Международного энергетического агентства, именно они ложатся в основу стратегической оценки нефтегазовыми компаниями возможного влияния развития климатической политики на проекты компаний в соответствии с тем или иным сценарием. Надо иметь в виду, что прогнозы и сценарии МЭА разрабатываются с учетом международных обязательств стран в рамках Парижского соглашения и политических деклараций о намерениях достичь 
климатической нейтральности на национальном уровне. Такие обязательства взяли на себя уже несколько стран (Австрия, Великобритания) и крупных городов и регионов в США, поэтому принимать в расчет такие перспективы энергетический бизнес обязан.

Для управления стратегическими рисками компании проводят модельную оценку своих активов, принимая в расчет допущения, лежащие в основе Сценария устойчивого развития МЭА (Sustainable Development Scenario, SDS).

Сценарий SDS предполагает, что эмиссии CO2 достигнут пика уже сейчас (в 2019-2020 гг.) на уровне 33-34 Гт, а затем будут снижаться средним темпом 3,8\% в год до уровня менее 10 Гт к 2050 г. и до нуля к 2070 г. В случае реализации сценария SDS накопленный объем эмиссий СО2 в период 2018-2070 гг. составит 880 Гт. Это означает, что остаточный объем допустимых эмиссий СO2 составляет немногим более 800 Гт в период 2021-2070 гг.

Это значит, что модель МЭА обозначает целевой показатель для мировой экономики: за все последующие годы допустимо эмитировать не более 800 Гт СО2-эквивалента. И исходя из этой цифры все экономические агенты могут формулировать собственные цели декарбонизации.

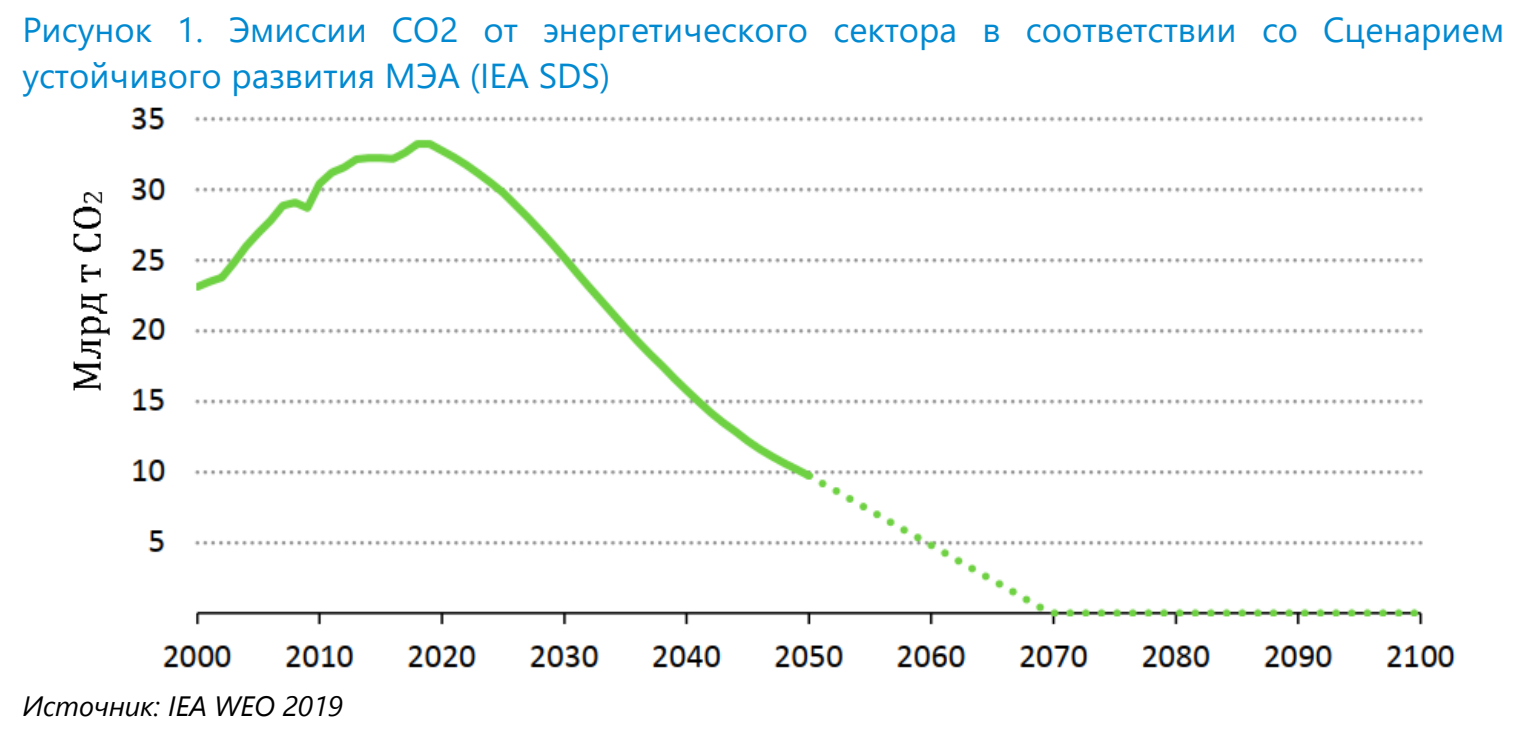

Например, взяв за основу своих модельных расчетов сценарий SDS, американская компания Occidental Petroleum в 2019 г. повысила прогноз будущих цен на углеродные эмиссии с $\$ 40$ до $\$ 50$ за метрическую тонну CO2 для будущих проектов с капитальными затратами, превышающими \$5 млн. При оценке операций компании по всему миру это оказалось эквивалентно увеличению себестоимости добычи углеводородного сырья на \$1,8 на каждый добытый баррель н.э.

Однако компания не видит существенного риска для своих активов, поскольку ее ресурсная база ориентирована на короткий инвестиционный цикл, а деловая стратегия предполагает строгое управление затратами. 
Компания Occidental Petroleum приведена в пример как яркий представитель типично американского подхода к управлению климатическими рисками. У компании полностью разработана и активно используется инфраструктура по улавливанию и использованию СО2 для целей повышения нефтеотдачи на проектах в США, что позволяет считать этот подход достаточной страховкой от возможных ограничений и введения платы за углеродные эмиссии. Occidental Petroleum рассчитывает быть достаточно привлекательной компанией для инвесторов при различных сценариях развития климатической политики, включая достижение целей Парижского соглашения.

МЭА со своей стороны отслеживает процесс развития торговли углеродными эмиссиями (квотами на выбросы CO2) в мире ${ }^{12}$. Введение платы за углерод может стать эффективным инструментом по трансформации мировой энергетики в сторону чистого развития, стимулировать инвестиции в низкоуглеродные технологии, содействовать развитию многостороннего сотрудничества и добиться синергетического эффекта для энергетики и климатической политики.

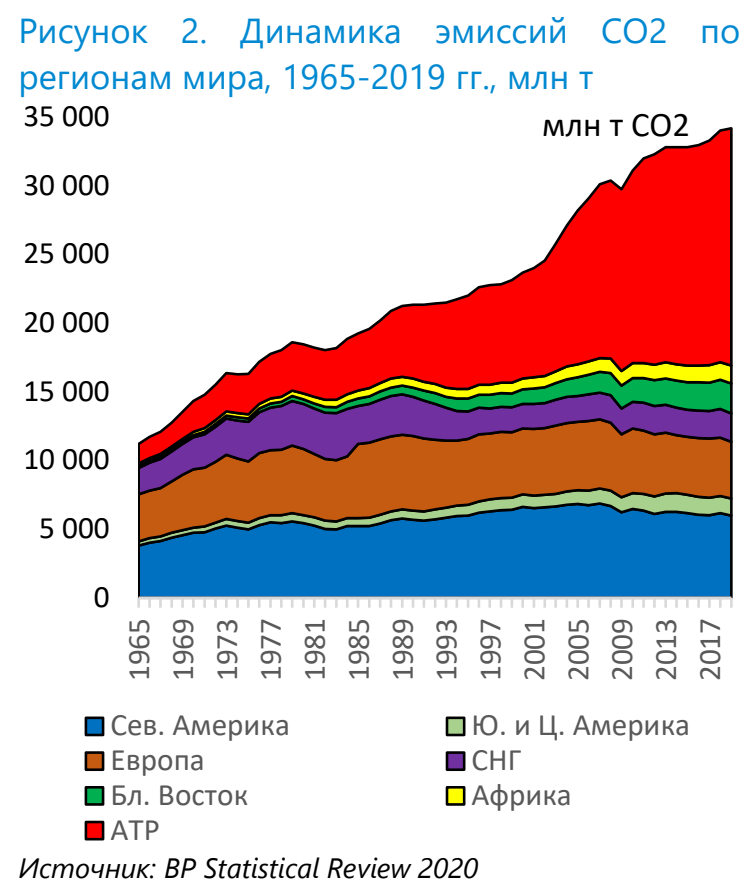

Рисунок 3. Прогноз эмиссий СО2 основными странами и регионами, 2018-2050 гг.

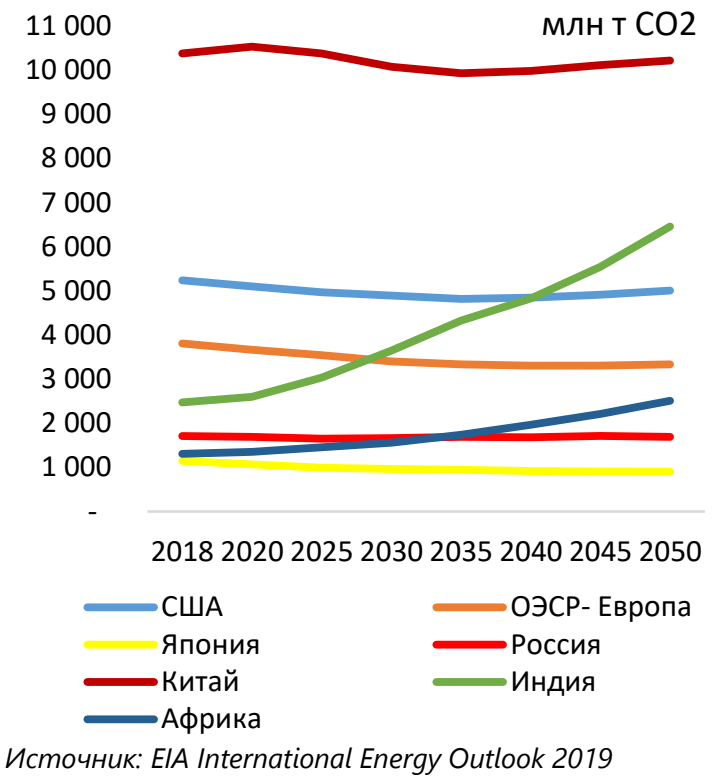

Системы торговли углеродными эмиссиями (квотами на выбросы CO2) создают стимулы для снижения эмиссий СО2 там, где это может быть наиболее экономически эффективно и позволяют наиболее полно учитывать климатические риски при принятии инвестиционных решений. В странах, где нет действующих механизмов ограничения эмиссий, предоставления квот и торговли эмиссиями, последствия возможной глобализации углеродного рынка можно оценивать только предположительно, что чревато неверной оценкой климатических рисков.

\footnotetext{
12 https://webstore.iea.org/implementing-effective-emissions-trading-systems-lessons-frominternational-experiences
} 


\section{Инвестиции в ВИЭ: взгляд Goldman Sachs}

В июне 2020 г. инвестиционный банк Goldman Sachs выпустил доклад «Карбономика. Зеленый двигатель восстановления экономики» (Carbonomics: The Green Engine of Economic Recovery) ${ }^{13}$, в котором утверждается, что возобновляемая энергия станет самым крупным объектом инвестиций в мировом энергетическом секторе в 2021 году, впервые в истории обойдя добычу нефти и газа.

В 2014 году доля ВИЭ в энергетических инвестициях составляла всего 15\%, однако, по прогнозу Банка, к 2021 году она вырастет до 25\%.

По прогнозам Goldman Sachs, инвестиции в «чистые технологии» и соответствующую «зеленую» инфраструктуру составят \$1-2 трлн ежегодно и позволят создать 15-20 миллионов рабочих мест. Эти инвестиции накопленным итогом могут составить до \$16 трлн к 2030 году, если вступят в силу проекты государственно-частного партнерства, предусмотренные, в частности, Европейским «Зеленым пактом» (European Green Deal).

По мнению Goldman Sachs, возобновляемая энергетика станет в 2021 году главным объектом инвестирования в энергетическом секторе благодаря изменениям в стоимости капитала, которая вырастет до 20\% для долгосрочных инвестиций в нефтегазовые проекты и снизится до 3-5\% для инвестиций в ВИЭ. Движущей силой этих тектонических сдвигов на рынках капитала становятся ожидания возможного введения углеродного налога, который, по оценке Goldman Sachs, может составить \$40-80 за тонну эмиссий углерода при новых проектах по разработке месторождений углеводородов.

При этом опасения относительно доступности энергоносителей могут замедлить развитие углеродного рынка, как это уже происходило при прошлых рецессиях, но введение углеродного налога и глобализация углеродного рынка способны переломить эту тенденцию. В 2018-2019 гг. средняя мировая цена 1 т выбросов СО2 оценивалась на уровне в \$23-25, тогда как для выполнения целей Парижского соглашения (удержать повышение средней температуры на планете к 2100 году в пределах 2 градусов по Цельсию при сохранении экономического роста) Комиссия высокого уровня по ценам на углерод, возглавляемая экономистами Николасом Стерном и Джозефом Стиглицем, рекомендовала уже к 2020 году довести цены на углерод до уровня \$40-80 за тонну CO2, а к 2030 году - до уровня \$50-100 долл. Таким образом, «углеродная глобализация» обладает большим потенциалом.

Эксперты Goldman Sachs считают, что возможно возникновение «двухскоростной» инвестиционной модели: фискальные и монетарные стимулы будут содействовать инвестициям в зрелые технологии ВИЭ, такие как как солнечная, ветровая энергетика и биотопливо. В то же время технологии, находящиеся на начальных

13 https://www.goldmansachs.com/insights/pages/gs-research/carbonomics-green-engine-ofeconomic-recovery-f/report.pdf 
стадиях разработки, такие как улавливание углерода и производство зеленого водорода, могут страдать от нехватки средств без более высоких цен за выбросы CO2.

Задержки с введением углеродных налогов могут быть компенсированы развитием добровольных углеродных рынков, но именно введение углеродных налогов необходимо для ускорения развития чистых энергетических технологий и достижения углеродной нейтральности.

Goldman Sachs отмечает ускорение преобразования международных нефтегазовых компаний (Big Oil) в энергетические компании широкого профиля (Big Energy). Если в 2019 году технологиям «новой энергетики» предназначалось 4\% инвестиционных бюджетов, то в 2021 году их доля повысится до 14\%.

Таким образом, происходящее сегодня фактическое обесценивание активов в нефтегазовом секторе обусловлено скорее растущей стоимостью привлечения капитала для реализации новых инвестиционных проектов в этой сфере, а не фундаментальным недостатком спроса на углеводородную продукцию. На этом фоне «зеленые» технологии (производство энергии на базе ВИЭ и пр.) достигли зрелости и готовы для еще более масштабного развёртывания, в особенности в условиях низкой стоимости капитала и при быстром развитии эффективной нормативно-правовой базы.

\section{Климатическая инициатива нефтегазовых компаний}

В июле 2020 г. Климатическая инициатива нефтегазовых компаний (Oil and Gas Climate Initiative, OGCI) установила цель по снижению средней углеродоемкости операций по разведке и добыче (upstream) компаний-участников Инициативы в диапазоне до 20-21 кг СО2-эквивалента на баррель нефтяного эквивалента к 2025 г. с базового уровня в 23 кг в 2017 году. ${ }^{14}$

OGCI - консорциум, объединяющий руководителей BP, Shell, Total, ExxonMobil, Chevron, CNPC, Eni, Equinor, Occidental, Petrobras, Repsol и Saudi Aramco - компаний, на которые приходится 30\% мировой добычи нефти и газа.

Указанный выше диапазон соответствует сокращению, необходимому нефтегазовой отрасли для поддержки целей Парижского соглашения, считает OGCI. Новая цель подразумевает снижение выбросов на 36-52 млн т СО2 в год к 2025 году (при условии постоянного уровня реализации нефти и газа).

OGCI заявляет, что хочет играть активную роль в ускорении глобального перехода к нулевым выбросам посредством коллективных практических действий. Новая цель является конкретным шагом в этом направлении.

Целевой показатель охватывает выбросы как двуокиси углерода, так и метана в результате разведки и добычи нефти и газа, осуществляемой компаниями-членами OGCI, а также выбросы от используемых в процессах электроэнергии и пара. OGCI

${ }^{14}$ https://oilandgasclimateinitiative.com/carbon-intensity-target-pr/ 
также будет работать над конкретными действиями по снижению выбросов от производства сжиженного природного газа (СПГ) и в результате использования технологии получения жидких углеводородов из газа (GTL), при этом углеродная интенсивность производства будет учитываться в расчете на единицу поставляемой на рынок продукции.

Отчетность об интенсивности выбросов углерода OGCI будет представляться на ежегодной основе и верифицироваться EY как независимой третьей стороной.

При этом задача снижения удельных выбросов не означает их снижение в абсолютном выражении при увеличении выпуска продукции. Члены OGCI ежегодно инвестируют свыше \$7 млрд в низкоуглеродные технологии. Новая цель OGCI охватывает только выбросы от основной деятельности, так называемые выбросы Уровней 1 и 2. Однако основной объём выбросов парниковых газов - это выбросы от потребления нефти и газа (выбросы третьего уровня), и для инвестиций в декарбонизацию отраслей промышленности и транспорта создан совместный инвестиционный фонд - OGCI Climate Investments с капиталом более \$1 млрд.

\section{Природоохранное партнерство нефтяников США}

С начала 2018 г. в США действует Партнерство по охране окружающей среды (Тhe Environmental Partnership) ${ }^{15}$, образованное компаниями нефтегазового сектора, заявившими о намерении улучшать экологические показатели своей работы. Участники партнерства предпринимают усилия по изучению и внедрению наилучших технологий по ответственной разработке и освоению национальных нефтегазовых ресурсов. Совместные действия участников партнерства призваны содействовать снижению эмиссий.

Участниками партнерства являются более 80 американских нефтегазовых компаний, представляющие 17 из 21 штата, где добывается нефть и газ. Число участников более чем утроилось за два с половиной года действия партнерства, среди них - 19 из 20 крупнейших производителей нефти и 36 из 40 крупнейших производителей газа в США.

Природоохранное партнерство, в первую очередь, сосредоточено на изучении, распространении и содействии во внедрении технических решений, которые показали себя как наиболее рентабельные и эффективные способы снижения эмиссий углерода. Партнерство разработало три отдельных программы, основанные на данных Национального агентства по охране окружающей среды и призванные сократить эмиссии метана и летучих органических соединений.

Программа по модернизации и замене устаревшей управляющей аппаратуры, которая является главным источником утечек метана, должна обеспечить 100\%-ю замену некачественного оборудования и в течение пяти лет снизить до минимума

${ }^{15}$ https://theenvironmentalpartnership.org/ 
или вовсе ликвидировать этот источник эмиссий. Партнерство будет ежегодно собирать данные о количестве замененных пневматических контроллеров.

Две другие программы, продвигаемые партнерством - программа удаления жидкости из газовых скважин и программа ликвидации утечек нефти и газа из трубопроводов. Обе программы предполагают, что участники проводят тщательный мониторинг состояния оборудования, ликвидируют источники эмиссий и сообщают о результатах партнерству, которое ежегодно публикует отчет о количестве обследованных участков и обнаруженных источниках эмиссий.

Среди организаторов и координаторов Природоохранного партнерства неявно присутствует Американский нефтяной институт (API) - лоббистская организация, продвигающая интересы американских нефтегазовых компаний. В данном случае проблема борьбы с изменением климата и развития чистой энергетики сводится к чисто техническим вопросам своевременной замены клапанов и задвижек и борьбой с утечками сырья в рамках традиционной модели нефтегазового бизнеса, и не вполне понятно, есть ли какой-то политический смысл в таком упрощении темы и принижении значения глобального перехода к низкоуглеродной энергетике. Возможно, партнерство хочет подать пример того, что и на низовом технологическом уровне можно добиться существенных результатов для защиты природной среды.

\section{Обзор планов неббтегазовых мейджоров по достижению углеродной нейтральности}

BP

В феврале 2020 г. британская компания ВР объявила, что намерена стать «углероднонейтральной» и достичь нулевого баланса выбросов CO2 (net zero) к 2050 году «или раньше»16. Новый глава компании Бернард Луни заявил: «Мы ожидаем, что со временем будем больше инвестировать в низкоуглеродные предприятия - и меньше в нефть и газ. Цель состоит в том, чтобы разумно вкладывать в бизнес, где мы можем увеличивать стоимость, развиваться в большом масштабе и обеспечивать конкурентоспособную прибыль». В заявлении разъясняется, что ВР намерена и впредь приносить хороший доход инвесторам, одновременно осуществляя энергетический переход.

По расчётам ВР, для достижения заявленной цели будет необходимо сократить выбросы CO2 на 415 млн т (55 млн т - от операционной деятельности и 360 млн т, содержащихся в добываемых нефти и газе). Компания также будет стремиться сократить углеродоемкость продуктов, которые она продаёт, на 50\% к 2050 году.

\footnotetext{
${ }^{16}$ https://www.bp.com/en/global/corporate/who-we-are/reimagining-energy.html
} 
В августе 2020 г. ВР обнародовала свою стратегию на ближайшие десять лет, предполагающую превращение из международной нефтяной компании в интегрированную энергетическую компанию. ${ }^{17}$

Стратегия сфокусирована на трех основных направлениях:

Низкоуглеродная энергетика. Развитие возобновляемой энергетики и биоэнергетики, укрепление позиций на водородном рынке и в технологиях улавливания и хранения/использования углерода (CCUS), обеспечение потребителей достаточными ресурсами газа для поддержки низкоуглеродной энергетики.

Удобство и мобильность. Потребители становятся в центр всего, что делает компания. Поддержка глобальной революции в мобильности, перестройка розничных продаж в направлении наибольшего удобства, расширение присутствия на топливных рынках развивающихся стран.

Фокус на устойчивых и безопасных поставках углеводородов. Концентрируясь на вопросах безопасности и надежности поставок, ВР стремится повышать доходность операций при снижении эмиссий. Компания намерена завершить текущие крупные проекты, снизив их капиталоемкость и сделав упор на производстве меньших объемов более конкурентоспособной продукции. Компания не будет заниматься поисково-разведочными работами в странах, где в настоящее время у нее нет добывающих активов. Акции «Роснефти» остаются важной частью портфеля ВР и обеспечивают компании сильные позиции в России.

К 2030 году ВР должна стать совершенно другой компанией. Поставлены следующие цели:

Инвестиции в низкоуглеродные источники энергии должны вырасти с $\$ 500$ млн в год до \$5 млрд в год;

Установленная мощность ВИЭ должна вырасти с 2,5 ГВт в 2019 г. до примерно 50 ГВт;

Производство биотоплива должно вырасти с 22 тыс. барр. в сутки до более 100 тыс. барр. в сутки;

Водородный бизнес должен вырасти, обеспечив 10\%-ю долю компании на ключевых рынках;

Глобальное число взаимодействий с потребителями должно вырасти с 10 млн до 20 млн в день;

Число зарядных станций для электромобилей должно вырасти с 7,5 тыс. до более 70 тысяч;

Должно быть образовано энергетическое партнерство с 10-15 крупными городами и тремя ключевыми отраслями промышленности.

${ }^{17}$ https://www.bp.com/en/global/corporate/news-and-insights/press-releases/frominternational-oil-company-to-integrated-energy-company-bp-sets-out-strategy-for-decade-ofdelivery-towards-net-zero-ambition.html 
В эти же сроки добыча нефти и газа должна снизиться с 2,6 млн барр. в сутки в 2019 г. до около 1,5 млн барр. в сутки, а объемы нефтепереработки - с 1,7 млн барр. в сутки в 2019 г. до примерно 1,2 млн барр. в сутки.

В процессе трансформации компания продолжит обращать особое внимание на безопасность, эффективность операций и финансовую дисциплину.

\section{Chevron}

Американская компания Chevron заявляет о действиях в отношении проблемы изменения климата, которые заключаются в экономически эффективном снижении углеродной интенсивности своих операций, развитии технологий возобновляемой энергетики для поддержки основного нефтегазового бизнеса и инвестировании в прорывные технологии.

Приоритетное отношение к защите окружающей среды - не новый подход Chevron, он является составной частью стратегии компании по взаимоотношениям с инвесторами и акционерами под названием The Chevron Way. В ответ на интерес инвесторов Chevron c 2017 года начал добровольно публиковать ежегодные климатические доклады, используя рекомендации Рабочей группы по раскрытию климатической финансовой информации (Task Force for Climate-related Financial Disclosures, TCFD). Эти доклады разъясняют стратегический подход компании к принятию решений об инвестировании, основанный на оценке климатических рисков и возможностей.

\section{Eni}

Долгосрочный стратегический план развития Eni до 2050 г. предполагает достижение следующих целей:

- Рост добычи нефти и газа на 3,5\% в год до 2025 г. при снижении доли нефти в добыче. К 2050 г. газ составит до 85\% в общем объеме добычи углеводородов компании.

- Реализация проектов по хранению углерода (CCS) в объемах свыше 40 млн т к 2050 г.

- Приоритетное инвестирование в производство электроэнергии на газовых электростанциях, работающих в сочетании с CCS-установками и ВИЭ.

- Рост установленной мощности ВИЭ до 55 ГВт к 2050 г., главным образом в странах ОЭСР. Число клиентов компании, получающих энергию из возобновляемых источников, должно превысить 20 млн. к 2050 году.

- Постепенное переоборудование НПЗ в Италии с использованием новых технологий производства декарбонизированных топлив из переработанных отходов, что должно привести к увеличению производства биотоплива до 5 млн т в год с отказом от использования пальмового масла с 2023 г. - на 7 лет раньше, чем предполагается планами EC. 
- Переоборудование существующих автозаправочных станций в станции, реализующие синтетические топлива нового поколения.

Долгосрочная стратегия Eni предполагает снижение эмиссий CO2 всех уровней на $80 \%$ к 2050 г. (это касается полного цикла использования продукции в течение всего срока использования) и сокращение углеродной интенсивности на 55\% по сравнению с 2018 г.

Промежуточные цели касаются достижения нулевого углеродного следа к 2030 г. для эмиссий СО2 от добывающих проектов и нетто-нулевого углеродного следа для эмиссий CO2 всей группы Eni к 2040 г.

Основным способом снизить эмиссии в ближайшие пять лет для компании будет снижение объемов сжигания попутного газа, которое в 2018 г. было ответственно за $27 \%$ всех эмиссий от операций компании. При этом в 2018 г. Eni удалось снизить объемы сжигания попутного газа на 9\% за счет снижения до нуля этого показателя на проектах компании в Туркменистане. Eni также инвестировала около \$130 млн в проекты по сокращению сжигания попутного газа в Нигерии.

\section{Equinor}

Норвежский нефтегазовый концерн Equinor объявил, что обязуется достичь нулевого уровня выбросов от своей деятельности к 2050 году. Equinor выпустил новую дорожную карту по климату, «направленную на обеспечение конкурентоспособной и устойчивой бизнес-модели в процессе энергетического перехода, пригодной для долгосрочного создания стоимости и соответствующей Парижскому соглашению».

Equinor стремится:

- снизить углеродную интенсивность своей деятельности во всей цепочке, включая конечное потребление энергетических продуктов, реализуемых компанией, как минимум на 50\% к 2050 году;

- увеличить мощность возобновляемой энергетики в портфеле компании в 10 раз к 2026 году и стать крупнейшей компанией в мире в сфере ветроэнергетики;

- укрепить свои лидирующие позиции в отрасли по углеродноэффективному производству, обеспечить углеродно-нейтральные глобальные операции к 2030 году.

Стремление снизить чистую углеродную интенсивность как минимум на $50 \%$ к 2050 году учитывает объемы выбросов уровней 1, 2 и 3, то есть от начального производства до конечного потребления.

В соответствии с планами компании, к 2050 г. на каждую единицу произведенной энергии, в среднем, будет приходиться менее половины выбросов по сравнению с сегодняшним днем. Ожидается, что задачи будут выполнены в основном за счет значительного роста возобновляемых источников энергии и изменений в масштабах и составе нефтегазового портфеля. Операционная эффективность, CCUS и водород также будут важны, а в качестве дополнения могут использоваться признанные 
механизмы компенсации (системы торговли квотами, такие как EU ETS) и естественные поглотители СО2.

К 2026 г. Equinor ожидает, что энергетические мощности компании, работающие на основе ВИЭ, составят от 4 до 6 ГВт, а к 2035 г. Equinor планирует увеличить мощности возобновляемых источников энергии до 12-16 ГВт.

B 2019 г. Equinor выиграл право на строительство крупнейшей офшорной ветровой электростанции Dogger Bank мощностью 3,6 ГВт в британской акватории Северного моря. После ввода в эксплуатацию в середине 2020-х гг. эта электростанция будет вырабатывать примерно 5\% электроэнергии, потребляемой Великобританией.

В январе 2020 г. Equinor объявила о новых целях компании по сокращению абсолютных выбросов парниковых газов на эксплуатируемых морских месторождениях и береговых предприятиях в Норвегии: на 40\% к 2030 году, на 70\% к 2040 году и доведения таких выбросов до нуля к 2050 году. Эти цели планируется реализовать через проекты электрификации основных производственных процессов, внедрение дополнительных мер по повышению энергоэффективности, создание новых производственно-сбытовых цепочек, включающих установки по улавливанию и хранению углерода, а также развитие производства водорода.

Equinor является одним из мировых лидеров в применении технологий CCUS и занимается улавливанием и хранением CO2 на сторонних промышленных площадках. Углеродно-эффективная добыча нефти и газа будет все больше становиться конкурентным преимуществом, и Equinor будет стремиться обеспечить высокую стоимость и надежный нефтегазовый портфель.

Equinor стремится снизить интенсивность выбросов CO2 при добыче нефти и газа в глобальном масштабе до уровня ниже 8 кг на баррель нефтяного эквивалента к 2025 году, на пять лет раньше, чем прежде планировалось. Текущий мировой средний показатель по отрасли составляет 18 кг СО2 на баррель.

Климатическая дорожная карта компании также содержит задачу сохранить выбросы метана на уровне, близком к нулю, и полностью ликвидировать сжигание попутного газа к 2030 году.

\section{ExxonMobil}

ExxonMobil внимательно рассматривает возникающие риски, включая риск угрозы природной среде, и стремится управлять этими рисками на каждом этапе развития бизнеса. Подход компании к управлению экологическими рисками основан на глубоком изучении воздействия на окружающую среду всех операций компании. Действующая в компании Интегрированная система управления операциями (Operations Integrity Management System) позволяет включать в себя действия в рамках корпоративной экологической политики для управления соответствующими рисками. 
Система управления вопросами охраны окружающей среды (Environmental management system) ${ }^{18}$ действует в компании в рамках корпоративной философии «Защити завтрашний день сегодня» (Protect Tomorrow Today), предполагающей следование единым экологическим стандартам при операциях компании по всему миру.

Несмотря на яркую природоохранную риторику, практические действия ExxonMobil ограничиваются продвижением газовых проектов, включая экспорт СПГ. Компания не прекращает доказывать преимущества газа по отношению к углю.

Компания также продолжает внедрять эффективные методы по снижению эмиссий метана и других газов при различных операциях, но не объявляет никаких обязательств по снижению углеродной интенсивности своего бизнеса. Упоминается, что членом партнерств по снижению уровней сжигания попутного газа стало подразделение ExxonMobil, занимающееся сланцевыми проектами на территории США - XTO Energy, но головная компания подобных обязательств на себя не берет.

\section{Occidental Petroleum}

Occidental Petroleum стала первой американской компанией, которая присоединилась к инициативе Всемирного банка по сокращению до нуля сжигания попутного газа к 2030 году - 'Zero Routine Flaring by 2030'. Цель - снизить эмиссии и повысить использование ценного энергоресурса.

Occidental Petroleum обязуется значительно снизить свой углеродный след, включая эмиссию углерода от использования продаваемых продуктов. Компания изучает разные возможности внести свой вклад в достижение углеродной нейтральности по всей цепочке создания стоимости. Инвестиции в ключевые технологии будут производиться по всему спектру. Это касается как снижения прямых эмиссий, косвенных, а также связанных с использованием продукции - уровни 1, 2 и 3 (Scopes 1, 2 и 3). Также имеются в виду инвестиции в технологии улавливания, утилизации и хранения углерода (CCUS) и снижение эмиссий у партнеров, где Occidental Petroleum может использовать свои технологии и ноу-хау для снижения углеродного следа.

В краткосрочной перспективе ключевым бизнесом Occidental Petroleum по снижению эмиссий остается CCUS. Компания развивает проекты по прямому улавливанию CO2 из атмосферы и из сторонних источников с последующим использованием для повышения нефтеотдачи. В долгосрочных планах у компании расширить способы коммерческого использования $\mathrm{CO} 2$. Для поддержки действий по достижению углеродной нейтральности компания разрабатывает методологию по обеспечению прозрачности и надежному измерению общей углеродной интенсивности своего бизнеса.

\footnotetext{
${ }^{18}$ https://corporate.exxonmobil.com/Community-engagement/SustainabilityReport/Environment/Environmental-management-system
} 


\section{Repsol}

Испанский нефтегазовый концерн Repsol стал первой компанией, заявившей о намерении добиться чистых нулевых выбросов от своей деятельности (net zero emissions) к 2050 году. Repsol заявила, что деятельность концерна будет соответствовать «энергетическому переходу и усилиями по ограничению повышения температуры на планете до уровня ниже 2 градусов по Цельсию в соответствии с климатическими целями Парижского соглашения».

Для достижения новой цели потребуется полный пересмотр деловой активности концерна, в том числе постепенный переход от нефтегазового бизнеса к производству биотоплива и химических продуктов, которые имеют более низкий углеродный след, а также расширение активности в электроэнергетике. Repsol планирует увеличить свои мощности в низкоуглеродной электроэнергетике до 7500 МВт к 2025 году, сократить утечки метана и начать реализовывать специальные меры, такие как внедрение технологий улавливания углерода.

Такими способами Repsol сможет сократить выбросы на 70\%, а остальные 30\% придётся компенсировать с помощью восстановления лесов и других «естественных поглотителей». Repsol также устанавливает промежуточные цели: углеродная интенсивность компании должна снизиться на 10\% к 2025 г., на 20\% к 2030 г. и на $40 \%$ к 2040 г. Таким образом, основой объём сокращения выбросов переносится на довольно отдалённую перспективу.

Repsol также обновила свои внутренние целевые ориентиры будущей стоимости тонны выбросов СО2. Так, действующий в компании с 2018 г. норматив, определяющий цену выбросов тонны CO2 внутри компании в $\$ 25$, вырастет к 2025 г. до $\$ 40$, а к 2040 г. цена должна возрасти до $\$ 70$ за тонну С02 для нефтеперерабатывающих, химических, газовых и электроэнергетических активов компании. Это поможет более правильному управлению инвестициями компании, а также будет способствовать вложениям в возобновляемую энергетику, энергоффективность и замкнутую (циркулярную) экономику.

Repsol планирует интегрировать возобновляемую энергию в производство т.н. «зеленого» водорода, а также использовать возобновляемую энергию для энергоснабжения внутренних производственных процессов. Для реализации этой амбициозной задачи компания увеличила целевой показатель по развитию мощностей низкоуглеродной электрогенерации к 2025 г. с 3 до 7,5 ГВт.

В настоящее время Repsol владеет 2,95 ГВт мощностей возобновляемой энергетики, еще 1,08 ГВт находятся в процессе строительства. Совет директоров одобрил инвестиции в две фотоэлектрические станции и один ветропарк совокупной мощностью 1,6 ГВт. Вместе с этими проектами портфель ВИЭ компании составит 5,6 ГВТ.

\section{Shell}

Нефтегазовый концерн Shell взял на себя добровольное обязательство стать энергетической компанией с чистыми нулевыми выбросами (net-zero emissions energy business) к 2050 году. 
Shell заявила, что будет стремиться достичь чистых нулевых выбросов от производства своей продукции, что охватывает так называемые выбросы уровней (Scope) 1 и 2 - не позднее 2050 года. Речь идёт о выбросах от операционной деятельности и от использования энергии (энергоресурсов) компанией. Кроме того, компания будет стремиться снизить углеродное содержание реализуемых энергетических продуктов на 65\% к 2050 году (промежуточная цель: на $30 \%$ к 2035 году). Это выбросы «третьего уровня» (Scope 3).

Чтобы достичь своих целей, Shell нужно будет продавать больше продуктов с меньшей интенсивностью выбросов углерода, таких как возобновляемая энергия, биотопливо и водород. Ранее компания заявляла, что она хочет стать крупнейшей электроэнергетической компанией мира к началу 2030-х годов.

К поставленным целям компания будет двигаться тремя путями. Во-первых, к 2050 году будут обеспечены нулевые эмиссии от производства всех видов продукции и от всей потребляемой компанией энергии. Но основные эмиссии - это эмиссии третьего уровня, которые получаются от использования энергетических продуктов потребителями. Поэтому второе, что будет делать Shell - снизит углеродный след своих энергетических продуктов. Для этого компании нужно реализовывать больше низкоуглеродной энергии, такой как электроэнергия из возобновляемых источников, биотоплива и водород.

Третий шаг компании - помочь потребителям снизить углеродный след энергетической продукции. На этом этапе отчетливо заметен рекламный элемент: потребителям внушается мысль, что продукция Shell особенно дружественна к окружающей среде, ее углеродный след незначителен, даже если по качеству бензина это незаметно - возможно, эмиссии компенсируются где-то в других сегментах бизнеса компании.

\section{Total}

Французская Total объявила о планах добиться чистой нулевой эмиссии от своей деятельности к 2050 г. Заявление об этом компания сделала совместно с инициативной группой инвесторов Climate Action $100+{ }^{19}$, владеющих более $25 \%$ акций Total. Для достижения этой цели Total сделает три шага:

1. Нетто-нулевые эмиссии по всем мировым операциям Total к 2050 г. или раньше (scope 1+2);

2. Нетто-нулевые эмиссии от использования продукции Total в Европе к 2050 г. или ранее (scope $1+2+3)$;

3. Сокращение на $60 \%$ или более средней углеродной интенсивности потребителями энергетической продукции Total по всему миру к 2050 г. (менее 27,5 грамм СO2 на мегаджоуль) - с промежуточной целью снижения на $15 \%$ к 2030 г. и на $35 \%$ к 2040 г. (scope $1+2+3)$.

\footnotetext{
${ }^{19} \mathrm{https}: / /$ climateaction100.wordpress.com/
} 
Эти намерения поддержаны стратегией развития Total как компании, сочетающей нефтегазовый бизнес с низкоуглеродной энергетикой и углеродно-нейтральными решениями. Total считает, что эта низкоуглеродная стратегия обеспечит компании конкурентные преимущества и создаст долгосрочную ценность для акционеров.

Эта стратегия уже реализуется с 2015 г., когда Total стала ведущей мировой нефтегазовой компанией, снижающей углеродную интенсивность третьего уровня (scope 3) - с 2015 г. она снизилась на 6\%. Сегодняшние цели по снижению до уровня менее 27,5 г С02/МДж к 2050 г. - самые амбициозные среди всех мейджоров.

Total подтвердила цель довести установленную мощность своих активов возобновляемой энергетики до 25 ГВт к 2025 г. и продолжить развивать это направление бизнеса и дальше. В настоящее время Total направляет более $10 \%$ своих капитальных затрат на проекты низкоуглеродной электроэнергии - наивысший уровень среди мейджоров. До 2030 г. или ранее капвложения компании в низкоуглеродную энергетику составят 20\%.

B 2018 г. Total вложила \$300 млн в реализацию Плана по энергоэффективности (Energy Efficiency Plan), нацеленный на снижение эмиссий CO2 на один миллион тонн в год в нефтеперерабатывающем и химическом секторе. Это должно обеспечить повышение энергоэффективности компании на 1\% в год на протяжении пяти лет.

Таким образом, все рассмотренные европейские компании приняли на себя обязательства обеспечить нетто-нулевые эмиссии СО2 от своей деятельности к 2050 году, тогда как ни одна американская компания таких целей не объявляла. С другой стороны, при глубоком рассмотрении выясняется, что каждая компания имеет в виду собственный подход к снижению эмиссий и детали своей стратегии раскрывать не спешит. Поэтому следует продолжать следить за реализацией низкоуглеродных стратегий нефтегазовых мейджоров и за различными подходами к оценке климатических рисков, которые они применяют. 